\title{
A cortical GABA-5HT interaction in the mechanism of action of the antidepressant trazodone
}

\author{
Maria Rita Luparini ${ }^{\mathrm{a}}$, Beatrice Garrone ${ }^{\mathrm{a}}$, Marta Pazzagli ${ }^{\mathrm{b}}$, Mario Pinza ${ }^{\mathrm{a}}$, Giancarlo Pepeu ${ }^{\mathrm{b}, *}$ \\ ${ }^{a}$ Department of Pharmacology, ACRAF-Angelini Ricerche, 00040 S. Palomba-Pomezia, Rome, Italy \\ ${ }^{\mathrm{b}}$ Department of Pharmacology, University of Florence, Viale G. Pieraccini 6, 50139 Florence, Italy
}

Accepted 10 May 2004

Available online 8 September 2004

\begin{abstract}
The aim of the study was to investigate whether the antidepressant trazodone (TRZ), a serotonin-2 receptor antagonist/reuptake inhibitor, modifies $\gamma$-amino-butyric acid (GABA) extracellular levels in the cerebral cortex, by acting on 5-HT $\mathrm{H}_{2 \mathrm{~A}}$ receptors, and through this mechanism increases 5-HT levels. For this purpose the effect of TRZ on the release of GABA was studied in adult male rats in synaptosomes, cortical slices, and "in vivo" by microdialysis. In cortical slices, the release of both GABA and 5-HT was determined. GABA and 5-HT were identified and their levels quantified by HPLC. The inhibition of 5-HT uptake by TRZ was also measured. In synaptosomes, TRZ antagonized dose-dependently, at concentrations from $10^{-10}$ to $10^{-6} \mathrm{M}$, the increase in GABA release induced by $( \pm) \mathrm{DOI}_{\text {, a } 5-\mathrm{HT}} 2 \mathrm{~A} / 2 \mathrm{C}$ agonist, and the $\alpha$ receptor agonist phenylephrine, both $10^{-6} \mathrm{M}$. The $\mathrm{pIC}_{50}$ values were $8.31 \pm 0.24$, and $5.99 \pm 0.52$, respectively. In the same preparation, $\left[{ }^{3} \mathrm{H}\right] 5-\mathrm{HT}$ accumulation was inhibited by citalopram and TRZ with $\mathrm{pIC}_{50}$ of $7.8 \pm 0.44$ and $5.9 \pm 0.09$, respectively, a finding confirming the weak activity of TRZ in comparison with a SSRI.

In cortical slices, TRZ exerted a biphasic effect on GABA release. At concentrations from $10^{-10}$ to $10^{-7} \mathrm{M}$ it inhibited and from $10^{-6}$ to $10^{-4} \mathrm{M}$ increased GABA release. 5-HT release was enhanced by TRZ throughout the entire range of concentrations tested. However, the increase was delayed after low and rapid after high concentrations. AMI-193, a 5- $\mathrm{HT}_{2 \mathrm{~A}}$ antagonist $\left(10^{-10}\right.$ to $\left.10^{-5} \mathrm{M}\right)$, reduced GABA release in a dose-response manner, while it induced an increase of 5-HT outflow. On the contrary, $( \pm)$ DOI $\left(10^{-10}\right.$ to $\left.10^{-5} \mathrm{M}\right)$ increased GABA release and inhibited 5-HT levels. Perfusion with the $\mathrm{GABA}_{\mathrm{A}}$ receptor antagonist bicuculline was also followed by an increase in 5-HT release.

In microdialysis experiments, TRZ $1.25 \mathrm{mg} \mathrm{kg}^{-1}$ s.c. brought about a decrease in GABA extracellular levels, while an increase was found after the dose of $2.5 \mathrm{mg} \mathrm{kg}^{-1}$.

These findings demonstrate that TRZ, at concentrations which do not inhibit 5-HT uptake, reduces the cortical GABAergic tone by decreasing GABA extracellular levels, through the blockade of 5- $\mathrm{HT}_{2 \mathrm{~A}}$ receptors. The attenuation of GABAergic tone is responsible for an increase in 5-HT levels. A further increase also results from 5-HT uptake inhibition caused by higher doses of TRZ. The ensuing high 5-HT levels enhance GABA release, which in turn inhibits 5-HT release.
\end{abstract}

(C) 2004 Elsevier Inc. All rights reserved.

Keywords: $\gamma$-Amino-butyric acid (GABA); GABA-5HT interactions; Microdialysis; Serotonin (5-HT); Trazodone

Abbreviations: AMI-193, 8-[3-(4-fluorophenoxy)propyl]-1-phenyl1,3,8-triazaspiro[4.5]-decan-4-one; AUC, area under the curve; DOI, $( \pm)$ 2,5-dimethoxy-4-iodophenyl-2-aminopropane; GABA, $\gamma$-amino-butyric acid; 5-HT, serotonin; SARI, serotonin receptor antagonist/reuptake inhibitor; SSRI, selective 5-HT reuptake inhibitors; TCAs, tricyclic antidepressants; TRZ, trazodone.

* Corresponding author. Tel.: +39 554271 274; fax: +39 554271280

E-mail address: giancarlo.pepeu@unifi.it (G. Pepeu).

\section{Introduction}

Trazodone (TRZ) was introduced in the 1960s as an antidepressant drug and is still widely used (Baldessarini, 2001). Since it is a weak inhibitor of serotonin (5-HT) reuptake (Owens et al., 1997), it has been considered different from tricyclic antidepressant (TCAs) and selective serotonin reuptake inhibitors (SSRIs). Pazzagli et al. (1999) demonstrated that TRZ administration brings about a large increase in 5-HT extracellular level in rat's cerebral cortex. 
However, the increase in cortical 5HT levels following TRZ administration shows a different profile and time course when compared with the increase brought about by TCAs (Maione et al., 1997) and SSRIs (Bel and Artigas, 1992). Fuller et al. (1984) suggested that the predominant action of TRZ on 5-HT neuronal systems is a 5-HT receptor antagonism rather than the inhibition of 5-HT reuptake. Marek et al. (1992), comparing TRZ and fluoxetine, concluded that the preclinical and clinical data suggest that TRZ exerts its antidepressant action through an antagonism for $5-\mathrm{HT}_{2 / 1 \mathrm{C}}$ receptors, while fluoxetine likely acts as an antidepressant via inhibition of 5-HT uptake. According to Frazer (1997), TRZ is characterized by high affinity and antagonistic activity for $5-\mathrm{HT}_{2 \mathrm{~A}}$ receptors subtype, and a weak inhibition of the 5-HT transporter. These data led Stahl (1996) and DeVane (2000) to define TRZ as a SARI compound, i.e. a serotonin-2 receptor antagonist/reuptake inhibitor. However, it has not yet been defined by which mechanism the blockade of 5- $\mathrm{HT}_{2 \mathrm{~A}}$ subtype receptors results in the large increase in 5-HT extracellular levels observed by Pazzagli et al. (1999), which is presumably responsible for the antidepressant effect since, according to Blier and de Montigny (1994), the therapeutic effect of SSRIs and TCAs correlates with the increase in 5-HT extracellular levels in cortical areas brought about by these drugs.

Cozzi and Nichols (1996) demonstrated that selective 5- $\mathrm{HT}_{2 \mathrm{~A}}$ antagonists, such as ketanserin, spiperone, MDL100907 and ritanserin, inhibit $\mathrm{K}^{+}$-stimulated $\gamma$-aminobutyric acid (GABA) release from cortical slices. Conversely, Abi-Saab et al. (1999) found that local infusion of the 5$\mathrm{HT}_{2 \mathrm{~A} / 2 \mathrm{C}}$ agonist $( \pm)$ DOI $[( \pm)-2,5$-dimethoxy-4-iodophenyl2 -aminopropane], dose-dependently increases cortical extracellular GABA levels. They also observed the activation of cortical GABAergic interneurons by demonstrating an increase in Fos-like immunoreactivity, following $( \pm)$ DOI infusion, co-localized with glutamic acid decarboxylase immunoreactivity, a marker of the GABAergic neurons.

Therefore, since cortical GABAergic interneurons can be modulated by $5-\mathrm{HT}$, acting on $5-\mathrm{HT}_{2 \mathrm{~A} / 2 \mathrm{C}}$ receptors subtypes, the aim of this study was to investigate whether TRZ, by acting on $5-\mathrm{HT}_{2 \mathrm{~A}}$ receptor, modifies GABA extracellular levels in the cerebral cortex and through this mechanism increases 5-HT levels. For this purpose, the effect of TRZ on the release of GABA was studied on rat synaptosomes, cortical slices, and "in vivo" in the frontal cortex by microdialysis. In cortical slices, the release of both GABA and 5HT was determined. Finally, 5-HT uptake inhibition by TRZ was also assessed.

\section{Methods}

\subsection{Animals}

Adult male Sprague-Dawley rats (Harlan, Italy), weighing 250-300 g, were housed at constant temperature $\left(23 \pm 1{ }^{\circ} \mathrm{C}\right)$ and relative humidity $(50 \%)$. Food and water were freely available. All animal-use procedures conformed to the guidelines of the European Community's Council for Animal Experiments (DL 116/92).

\subsection{Drugs}

The following drugs were used: TRZ (ACRAF, Aprilia, Italy), 5-HT, GABA, tetrodotoxin (TTX) and $(+)$ bicuculline (Sigma, St. Louis, MO), $( \pm)$ DOI (RBI, Natick, MA), phenylephrine (Aldrich Chemical, Milwaukee, USA), AMI-193 (Tocris, Langford, Bristol). Citalopram was extracted in our laboratory from prescription tablets (Seropram, Lundbeck, Italy).

The compounds were dissolved in water, while bicuculline was dissolved in the medium used for slice perfusion solution containing $2 \%$ of $\mathrm{HCl} 0.1 \mathrm{~N} \mathrm{HCl}$. In microdialysis experiments, the drugs were directly dissolved in saline and injected s.c. $\left(1 \mathrm{ml} \mathrm{kg} \mathrm{kg}^{-1}\right.$ body weight), or dissolved in Ringer solution for local administration by reverse dialysis through the microdialysis probe.

\subsection{Synaptosome preparation}

The animals were killed by decapitation and the cortex was rapidly removed. Crude synaptosomes were prepared according to the method described by Gray and Whittaker (1962) with minor modifications. The cortex was homogenized in 40 volumes of $0.32 \mathrm{M}$ sucrose buffered with phosphate at $\mathrm{pH}$ 7.4. The homogenate was centrifuged at $1000 \times g$ for $5 \mathrm{~min}$ and synaptosomes were isolated from the supernatant by centrifugation at $12,000 \times g$ for $20 \mathrm{~min}$. The pellet was resuspended in a physiological salt solution with the following composition (mM): $\mathrm{NaCl} 125, \mathrm{KCl} 3, \mathrm{MgSO}_{4}$ 1.2, $\mathrm{CaCl}_{2}$ 1.2, $\mathrm{NaH}_{2} \mathrm{PO}_{4} 1.0, \mathrm{NaHCO}_{3} 22$ and glucose 10; pH 7.2-7.4; gassed with $95 \% \quad \mathrm{O}_{2}$ and $5 \% \mathrm{CO}_{2}$ and maintained at $37{ }^{\circ} \mathrm{C}$.

\subsection{Synaptosome release experiments}

The synaptosome suspension was distributed at the bottom of a set of parallel superfusion chambers maintained at $37{ }^{\circ} \mathrm{C}$ (Raiteri et al., 1974). Superfusion $(0.6 \mathrm{ml} /$ min) was started with standard medium continuously aerated with a mixture of $\mathrm{O}_{2}$ and $\mathrm{CO}_{2}(95 \% / 5 \%)$. After $36 \mathrm{~min}$ of superfusion to equilibrate the system, four separate 3-min fractions were collected. Synaptosomes were exposed to the compounds at the start of the first fraction as described in the results. The dead time of the system was $3 \min 45 \mathrm{~s}$.

The change in neurotransmitters release was calculated as percent variation over the first sample collected before drug application, taken as basal value. The effects of TRZ on neurotransmitter release were presented as percent variation respect to the controls. 


\subsection{Synaptosome uptake experiments}

5-HT uptake by the synaptosomes was measured according to the method of Perovic and Muller (1995). The synaptosomal fractions were diluted to achieve a final protein concentration of $0.6-0.8 \mathrm{mg} / \mathrm{ml}$ and, after a preincubation period of $30 \mathrm{~min}$, uptake was started by the addition of $\left.10 \mathrm{nM} \mathrm{[}{ }^{3} \mathrm{H}\right] 5$-HT. Non-specific uptake was determined in the presence of $10 \mu \mathrm{M}$ citalopram. After 20 min incubation at $37{ }^{\circ} \mathrm{C}$ in Krebs-Ringer buffer with the following composition $(\mathrm{mM}): \mathrm{NaCl} 125, \mathrm{KCl} 3, \mathrm{MgSO}_{4}$ 1.2, $\mathrm{CaCl}_{2} 1.2, \mathrm{NaH}_{2} \mathrm{PO}_{4} 1.0, \mathrm{NaHCO}_{3} 22$, glucose 10 , HEPES $25 ; \mathrm{pH} 7.4$, the reaction was stopped with icecold buffer by rapid vacuum filtration onto Unifilter GF/B filters. The filters were rapidly washed with $3 \mathrm{ml}$ of icecold buffer. The plates were allowed to dry for $30 \mathrm{~min}$ at $45{ }^{\circ} \mathrm{C}$ before addition of $35 \mu \mathrm{l} /$ well of scintillation liquid (MicroScint 20, Packard, Meriden, USA). The radioactivity on the filter was measured at least $16 \mathrm{~h}$ later using a TopCount NTX (Packard). Radioactivity accumulated by synaptosomes at $0-4{ }^{\circ} \mathrm{C}$ was routinely subtracted and temperature-dependent uptake was defined as the difference between the uptake at $37{ }^{\circ} \mathrm{C}$ and that at $0-4$ ${ }^{\circ} \mathrm{C}$. Protein content was determined according to the method of Bradford (1976) using albumin as reference standard.

Data from competition experiments were analyzed by computer-assisted non-linear regression analysis using the least square fitting program Prism (GraphPad Software). The "four parameter logistic equation" defined as sigmoidal dose-response (variable slope) was used to measure the compound response according to the following formula

$$
\begin{aligned}
Y= & \text { Bottom }+(\text { Top }- \text { Bottom }) \\
& /(1+10((\operatorname{LogEC} 50-X) \times \text { HillSlope })
\end{aligned}
$$

where $X$ is the logarithm of concentration; $Y$ is the response and starts at the Bottom and goes to the Top with a sigmoid shape. No constant parameters were added so that the lines were allowed to float in the plane.

\subsection{Release experiments with cortical slices}

The rats were killed by decapitation and the cortex rapidly removed and placed on ice. The cortical slices were prepared from the frontal pole, approximately in the region in which the microdialysis probe was inserted in the in vivo experiment. The frontal pole was cut, with a McIlwain tissue chopper, in $400 \mu \mathrm{m}$ thick slices weighing $44.5 \pm 4.36 \mathrm{mg}$ (mean \pm S.E.M.; $n=6)$. The slices were preincubated at $37{ }^{\circ} \mathrm{C}$ for $30 \mathrm{~min}$ in a medium with following composition $(\mathrm{mM}): \mathrm{NaCl} 125, \mathrm{KCl} 3$, $\mathrm{MgSO}_{4} 1.2, \mathrm{CaCl}_{2} 1.2, \mathrm{NaH}_{2} \mathrm{PO}_{4} 1.0, \mathrm{NaHCO}_{3} 22$ and glucose 10; $\mathrm{pH} 7.2-7.4$; gassed with $95 \% \mathrm{O}_{2}$ and $5 \%$ $\mathrm{CO}_{2}$. After preincubation, in each chamber, one slice was placed at the top of a set of 12 superfusion chambers (Brandel-Suprafusion system, Semat Technical, UK) thermostated at $37{ }^{\circ} \mathrm{C}$. Superfusion was started at the rate of $0.6 \mathrm{ml} / \mathrm{min}$ with standard medium continuously gassed with a mixture of $\mathrm{O}_{2}(95 \%)$ and $\mathrm{CO}_{2}(5 \%)$. After $60 \mathrm{~min}$ of superfusion to equilibrate the system, 10 separate 4min fractions were collected. Drugs were added at the start of the third fraction for $2 \mathrm{~min}$ and the changes in GABA and 5-HT release were monitored by collecting 4 min samples for $28 \mathrm{~min}$. The dead time of the system was $2 \mathrm{~min}$.

\subsection{Microdialysis procedures}

Adult male rats were anaesthetised with chloral hydrate (400 mg/kg, i.p.) and placed in a Kopf stereotaxic frame. A guide cannula (CMA/11) was then implanted in the frontal cortex with the following coordinates: AP $4.5 \mathrm{~mm}$, $\mathrm{L}-2.8 \mathrm{~mm}, \mathrm{DV}-4.5 \mathrm{~mm}$ from the bregma (Paxinos and Watson, 1982). The experimental procedure previously described by Pazzagli et al. (1999) was followed. Briefly, $24 \mathrm{~h}$ after surgery each rat was placed in a plexiglas cage and a pre-equilibrium Cuprophan CMA/11 microdialysis probe ( $2 \mathrm{~mm}$ long, $0.24 \mathrm{~mm}$ o.d.) was slowly lowered, via the guide cannula, into its frontal cortex. The flow rate was $1.3 \mu \mathrm{l} / \mathrm{min}$. After $2 \mathrm{~h}$ equilibrating period, fourteen 30-min dialysate samples were collected. Drugs were administered after the collection of the first three samples.

\subsection{5-HT determination}

5-HT levels in the superfusion fluid and the dialysate samples was quantified according to the method of Kilts et al. (1981). The method involves a solvent delivery pump (Model LC-10AD, Shimadzu, Kyoto, Japan), an electrochemical detector Coulochem II and a high performance analytical cell, both from ESA (Bedford, MA). The detector potential was maintained at $500 \mathrm{mV}$, the sensitivity range at $1 \mu \mathrm{A}$ and the filter at $10 \mathrm{~s}$. A rheodyne (Model $7725 \mathrm{I}$ ) with a $100 \mu \mathrm{l}$ sample loop was used for sample injection. Chromatographic separations were performed using an $8 \mathrm{~cm} \times 4.6 \mathrm{~mm}$ column packed with octadecylsilane (C18) on microparticulate $(3 \mu \mathrm{m})$ silica gel (ESA). The mobile phase was a mixture of citrate $0.1 \mathrm{M}, \mathrm{Na}_{2} \mathrm{HPO}_{4} 75 \mathrm{mM}$, sodium octansulfonate $0.75 \mathrm{mM}$ and $11 \%$ methanol $(\mathrm{v} / \mathrm{v})$. After adjusting to $\mathrm{pH}$ 3.9 with $\mathrm{NaOH} 15 \mathrm{~N}$, the mobile phase was filtered through a $0.22 \mu \mathrm{m}$ Millipore filter and degassed under vacuum. All separations were performed isocratically at a flow-rate of $1.5 \mathrm{ml} / \mathrm{min}$.

\subsection{GABA determination}

GABA levels in the superfusion fluid and in the dialysate samples was quantified by HPLC according to the method of Tonnaer et al. (1983), with minor 
modifications. The method involves precolumn derivatization with $o$-phthalaldehyde followed by separation on a C18 reverse-phase chromatography column coupled with fluorescence detection. HPLC was performed with two solvent delivery pumps, an autosampler and a sample cooler (Shimadzu, Kyoto, Japan). The column effluent was monitored with a Shimadzu model RF-551 fluorimeter (excitation wavelength $340 \mathrm{~nm}$, emission wavelength 450 $\mathrm{nm}$ ). A step by step binary gradient was used to separate the aminoacids present in the samples. Mobile phase A and $\mathrm{B}$ were composed by $0.1 \mathrm{M}$ acetate buffer ( $\mathrm{pH} 5.8$ ) in $20 \%$ and $80 \%$ methanol (Lichrosolv, Merck and Co., Rahway, NJ), respectively. The two phases were filtered through $0.22 \mu \mathrm{m}$ Millipore filters and degassed. Flow rate was $1.2 \mathrm{ml} / \mathrm{min}$.

\subsection{Statistical analysis}

$\mathrm{IC}_{50}$ and $\mathrm{EC}_{50}$ values were calculated by a non-linear regression analysis using the GraphPad Prism ${ }^{\circledR}$ software. Changes in GABA and 5-HT levels were expressed as percent variations over the mean of the samples collected before drug administration (baseline). The effects of the drugs were also expressed as areas under the curve (AUC) calculated as indicated in the figure legends. Means \pm S.E.M. of the experimental data are presented. To evaluate the statistical significance the generalised linear model (GLM) for repeated measures procedure was performed using the SPSS-Statistical Package, and the "non-linear regression" procedure has been performed using the GraphPad Software, 1999.

\section{Results}

\subsection{Effect of TRZ on GABA release from synaptosomes}

The spontaneous GABA release from superfused synaptosomes was $7.37 \pm 0.82 \mathrm{pmol} / \mu \mathrm{l}(n=6)$. The release was enhanced in a concentration-dependent manner by the addition of the $5-\mathrm{HT}_{2 \mathrm{~A} / \mathrm{C}}$ receptor agonist $( \pm) \mathrm{DOI}$, and phenylephrine, a selective $\alpha_{1}$ receptor agonist, at concentrations ranging from $10^{-8}$ to $10^{-5} \mathrm{M}$ (Fig. 1, insets in panels $\mathrm{A}$ and $\mathrm{B}$, respectively) for $2 \mathrm{~min}$. TRZ added to the superfusion fluid at concentrations ranging between $10^{-10}$ and $10^{-5} \mathrm{M}$ did not modify the spontaneous GABA release (data not shown). However, when TRZ was added together with $( \pm)$ DOI or phenylephrine $10^{-6} \mathrm{M}$, it reduced dosedependently the increase in GABA release induced by both agonists as shown in Fig. 1, panels A and B. The pIC 50 value of TRZ in inhibiting $( \pm)$ DOI-evoked increase was $8.31 \pm 0.24$, and the $\mathrm{pIC}_{50}$ value inhibiting phenylephrineevoked increase was $5.99 \pm 0.52$. The 200 -fold difference demonstrates that TRZ has a higher affinity for $5-\mathrm{HT}_{2 \mathrm{~A}}$ than for $\alpha_{1}$ receptors.

\subsection{Effect of TRZ on 5-HT reuptake}

As shown in Fig. 2, TRZ, 5-HT, and citalopram, in a concentration-dependent manner, inhibited $\left[{ }^{3} \mathrm{H}\right] 5-\mathrm{HT}$ accumulation by a cortical synaptosomal-enriched fraction at 37 ${ }^{\circ} \mathrm{C}$, while they were unable to antagonize $\left[{ }^{3} \mathrm{H}\right] 5$-HT passive diffusion at $0{ }^{\circ} \mathrm{C}$ (data not shown). The rank of the potency, expressed as $\mathrm{pIC}_{50}$, to inhibit the $\left[{ }^{3} \mathrm{H}\right] 5-\mathrm{HT}$ accumulation
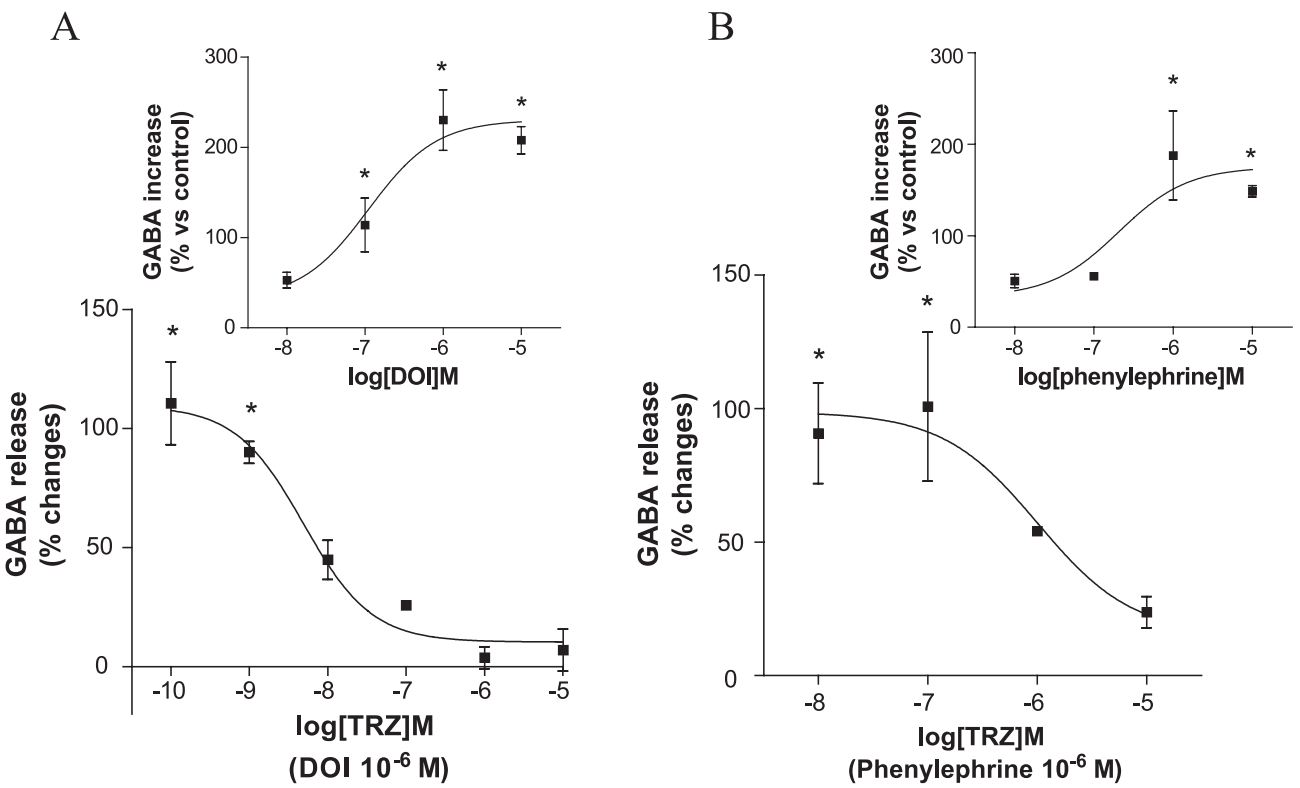

Fig. 1. TRZ antagonizes the increase in GABA release induced by $\left( \pm\right.$ )DOI $10^{-6} \mathrm{M}$ (Panel A) and phenylephrine $10^{-6} \mathrm{M}$ (Panel B) from rat cortical synaptosomes. The agonists were added to the superfusion medium for 2 min after baseline and TRZ was added for 8 min before and during agonist application. Insets: Per cent increase in GABA release induced by $( \pm$ )DOI (panel A) and phenylephrine (panel B). Each point is the mean \pm S.E.M. of four to six replicates expressed as percent changes vs. the baseline. Significance of differences between experimental groups are calculated vs. baseline values by ANOVA followed by Dunnett's test $(* p<0.05)$. 


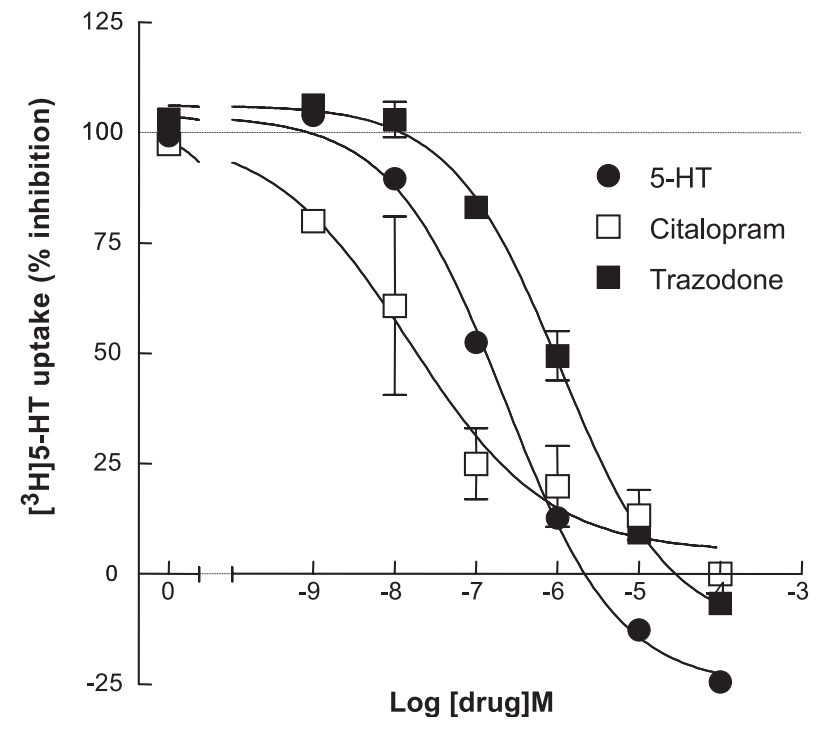

Fig. 2. Inhibition of $\left[{ }^{3} \mathrm{H}\right] 5-\mathrm{HT}$ accumulation in rat cortical synaptosomes

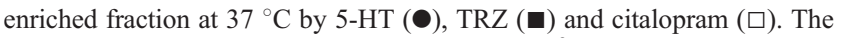
drug effects are expressed as percent variation of $\left[{ }^{3} \mathrm{H}\right] 5-\mathrm{HT}$ specific uptake. Each point is the mean \pm S.E.M. of six to eight replicates.

was: citalopram $7.8 \pm 0.44>5$-HT $6.6 \pm 0.11>$ TRZ $5.9 \pm 0.09$. The Hill slopes showed no significant differences between citalopram $(0.51 \pm 0.25), 5$-HT $(0.62 \pm 0.09)$ and TRZ $(0.64 \pm 0.08)$.

\subsection{Effect of TRZ on GABA and 5-HT release from cortical slices}

The effect of TRZ on spontaneous GABA and 5-HT release was investigated on cortical slices by adding different TRZ concentrations to the perfusion fluid for 2 min after the collection of three basal samples. After TRZ addition, the release was monitored for seven 4-min samples. The spontaneous outflows of GABA and 5-HT were $5.35 \pm 0.43 \mathrm{pmol} / \mu \mathrm{l}(n=6)$ and $0.02 \pm 0.001 \mathrm{pmol} / \mu \mathrm{l}$ $(n=6)$, respectively, and remained constant throughout the experiments. According to the concentration of TRZ added to the perfusion fluid, inhibition or stimulation of GABA release was observed. As shown in Fig. 3, panel A, the addition of TRZ $10^{-10} \mathrm{M}$ was followed by an immediate decrease in GABA release which fell by about $50 \%$ within $12 \mathrm{~min}$ and gradually returned to basal level. Conversely, after the addition of TRZ $10^{-4} \mathrm{M}$ a rapid increase in GABA release, lasting approximately 8 min was observed.

The concentration-dependent biphasic effect of TRZ on GABA release is illustrated in Fig. 3, panel B, in which the peak changes observed at each TRZ concentration tested is shown. The maximum decrease was observed at $10^{-10} \mathrm{M}$ and the shift from decrease to increase in GABA release occurred at $10^{-6} \mathrm{M}$.

The same TRZ concentrations were tested on 5-HT release, as shown in Fig. 4. After both applications of TRZ $10^{-10}$ and $10^{-4}$ an increase in 5-HT release was observed. However, the increase following $2 \mathrm{~min}$ application of
$10^{-10} \mathrm{M}$ occurred with a delay of $17 \pm 1.3 \mathrm{~min}$ and, after showing a rapid peak, faded rapidly. Conversely, the increase in 5HT release following TRZ $10^{-4} \mathrm{M}$ peaked within $4 \mathrm{~min}$, was larger and gradually returned to the basal level within 16 min.

In order to verify whether the delayed increase in 5HT release, following the addition of TRZ $10^{-10} \mathrm{M}$, depended on the decrease in extracellular GABA level, the GABAergic tone was reduced by the application for $2 \mathrm{~min}$ of bicuculline, a $\mathrm{GABA}_{\mathrm{A}}$ receptor antagonist, at concentrations ranging from $10^{-9}$ to $10^{-5} \mathrm{M}$. Fig. 5 shows that bicuculline brought about a dose-dependent increase in 5-HT release. The increase occurred with a delay of $12 \pm 1.8 \mathrm{~min}$ from bicuculline application and lasted about $12 \mathrm{~min}$.

After demonstrating that TRZ at low concentrations inhibits GABA release and increases 5-HT release presumably through a GABAergic mechanism, we attempted to
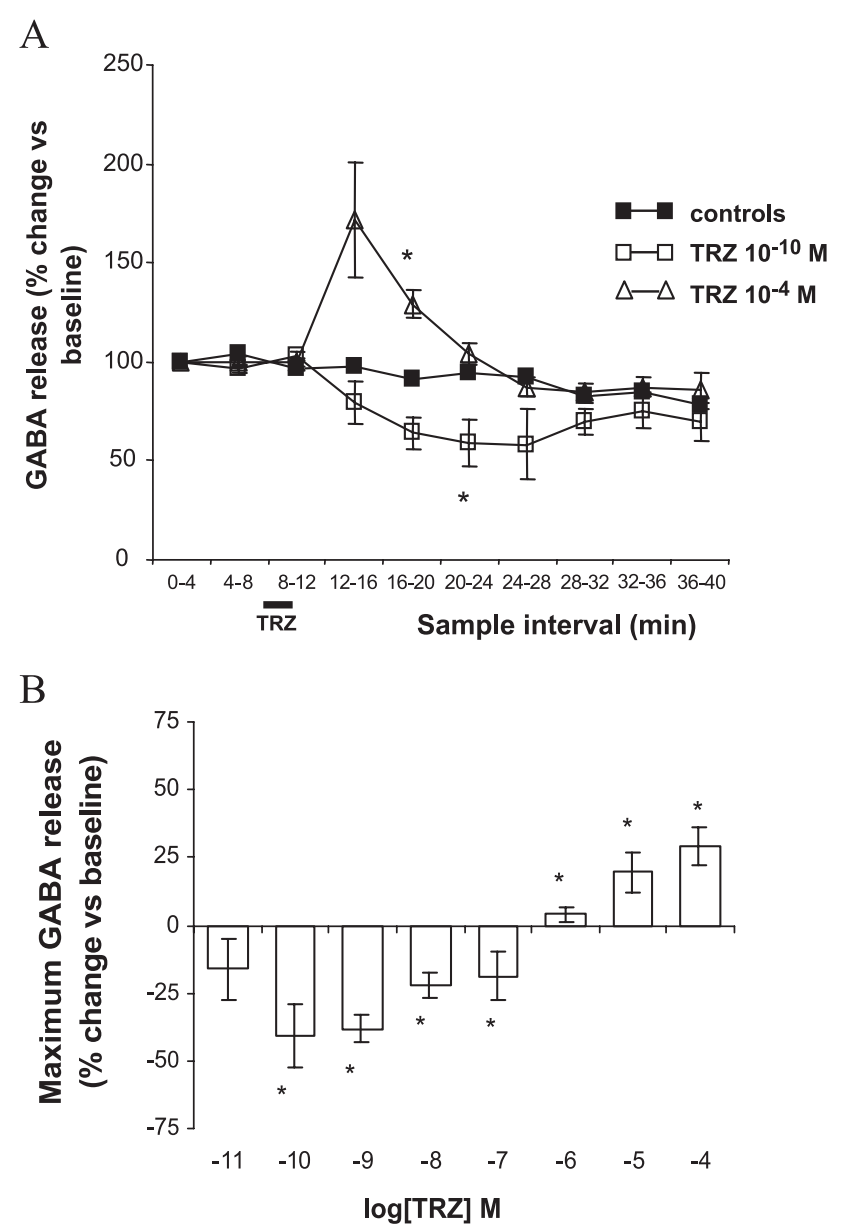

Fig. 3. Effect of TRZ on GABA release from rat cortical slices. Panel A: time course of the changes in GABA release induced by different TRZ concentrations. The first three samples are taken as baseline release. TRZ was added to the superfusion medium for $2 \mathrm{~min}$ after baseline as shown by the horizontal bar under the abscissa. Panel B: Peak percent changes in GABA release in the concentration range of $10^{-11}-10^{-4} \mathrm{M}$. Values are the mean \pm S.E.M of four to six samples expressed as percent changes vs. baseline. Significance of differences between experimental groups are calculated vs. control group by GLM for repeated measures $\left({ }^{*} p<0.05\right)$. 


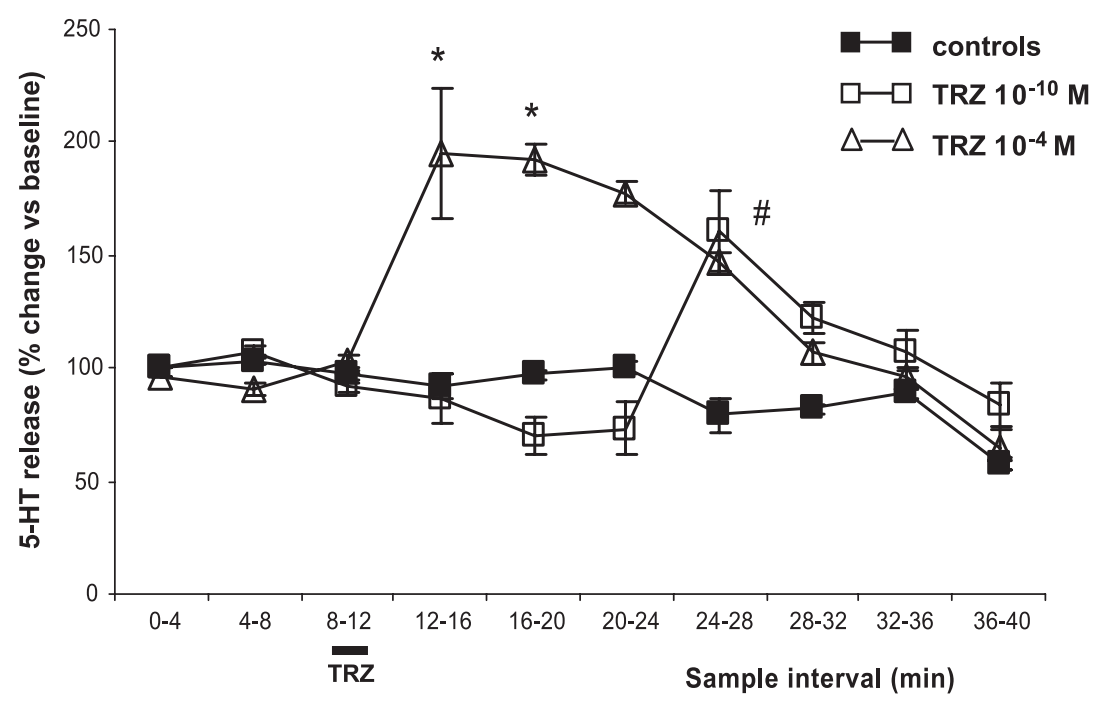

Fig. 4. Effect of different concentrations of TRZ on 5-HT release from rat cortical slices. The first three samples are taken as baseline release. TRZ was added to the superfusion medium for $2 \mathrm{~min}$ after baseline as shown by the horizontal bar under the abscissa. Values are the mean \pm S.E.M. of four to six samples expressed as percent changes vs. baseline. Significance of differences between experimental groups are calculated vs. control group by GLM for repeated measures $(* p<0.05)$.

define the receptor subtype involved by comparing the effects of TRZ with those of the selective 5- $\mathrm{HT}_{2 \mathrm{~A}}$ antagonist AMI-193 (Ismaiel et al., 1993) and partial agonist ( \pm )DOI (Appel et al., 1990), on GABA and 5-HT release. As illustrated by Fig. 6, Panel A, AMI-193 $\left(10^{-10}\right.$ to $\left.10^{-5} \mathrm{M}\right)$ brought about a concentration-dependent $\left(\mathrm{pEC}_{50}=9.35 \pm 0.28\right)$ rapid decrease in GABA release and a delayed $(12 \pm 1.6 \mathrm{~min})$ increase $\left(\mathrm{pEC}_{50}=8.50 \pm 0.24\right)$ in 5HT extracellular levels (Fig. 6, panel B). Conversely, the agonist $( \pm)$ DOI $\left(10^{-10}\right.$ to $\left.10^{-5} \mathrm{M}\right)$ brought about an increase in GABA release (Fig. 7, panel A) associated, after

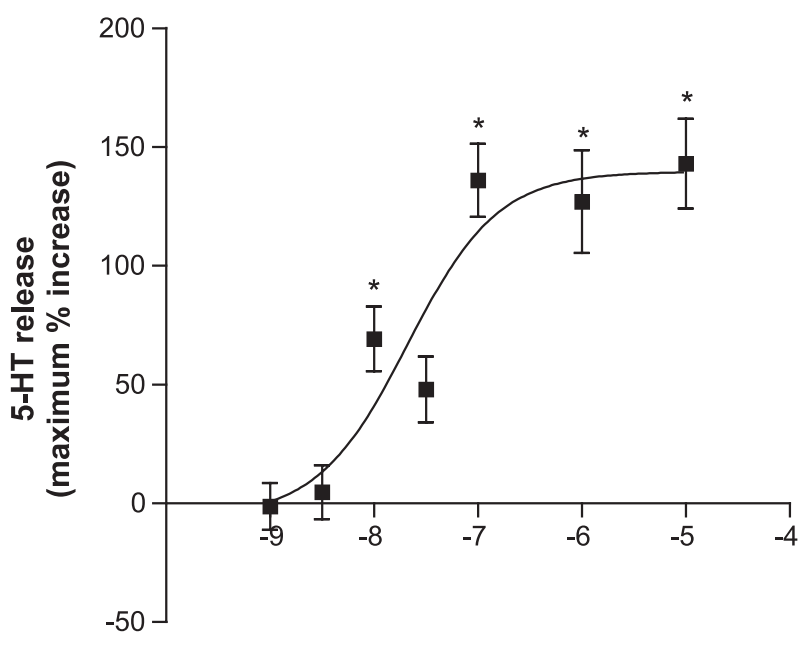

$\log [$ bicuculline]M

Fig. 5. Dose-response curve of bicuculline $\left(10^{-9}\right.$ to $\left.10^{-5} \mathrm{M}\right)$ on 5-HT release from rat cortical slices. The data represent the maximal effect for each bicuculline concentration expressed as percent of variation of release compared to the basal. Each point is the mean \pm S.E.M. of four to six replicates. Significance of differences between experimental groups are calculated vs. control group by GLM for repeated measures $\left({ }^{*} p<0.05\right)$. a delay of $17 \pm 1.0 \mathrm{~min}$, with a decrease in 5 -HT outflow (Fig. 7, panel B) with a $\mathrm{pEC}_{50}$ values of $8.18 \pm 0.22$ and $8.35 \pm .30$, respectively.

\subsection{Effect of TRZ on GABA "in vivo": microdialysis experiments}

The aim of this group of experiments was to verify whether also systemic TRZ administration modulates cortical GABAergic activity. For this purpose, extracellular levels of GABA were measured in the cerebral cortex, by the microdialysis technique, after TRZ injection. The results are shown in Fig. 8. The basal levels of GABA were $0.05 \pm 0.02 \mathrm{pmol} / \mu \mathrm{l}(n=15)$ and tended to decrease gradually over time (as showed in the control group). TRZ, injected at the dose of $1.25 \mathrm{mg} \mathrm{kg}^{-1}$ s.c., brought about a long-lasting decrease in GABA level peaking after about $1 \mathrm{~h}$. The decrease was statistically significant as demonstrated by calculating the change in AUC $(F=8.765 ; p=0.042)$ shown in the inset. Conversely, the administration of TRZ at the dose of $2.5 \mathrm{mg} \mathrm{kg}^{-1}$ s.c. was followed by a large, delayed, long lasting increase in GABA levels peaking after $4 \mathrm{~h}$. The increase was statistically significant $(F=29.036 ; p=0.006)$ as demonstrated by the change of the AUC, shown in the inset.

Confirmation that the biphasic changes in GABA extracellular level in the cortex depend upon a direct effect of TRZ on cortical neuronal circuitry was sought by administering the drug locally by reverse dialysis. As illustrated by Fig. 9, TRZ perfusion for $90 \mathrm{~min}$ at the concentration of $0.03 \mathrm{ng}^{-1} \mathrm{l}^{-1}$ was followed by a long lasting decrease in GABA extracellular level with a statistically significant $(F=7.150 ; p=0.032) 50 \%$ decrease in the AUC. Conversely, the perfusion with TRZ at the concentration of 
(A)

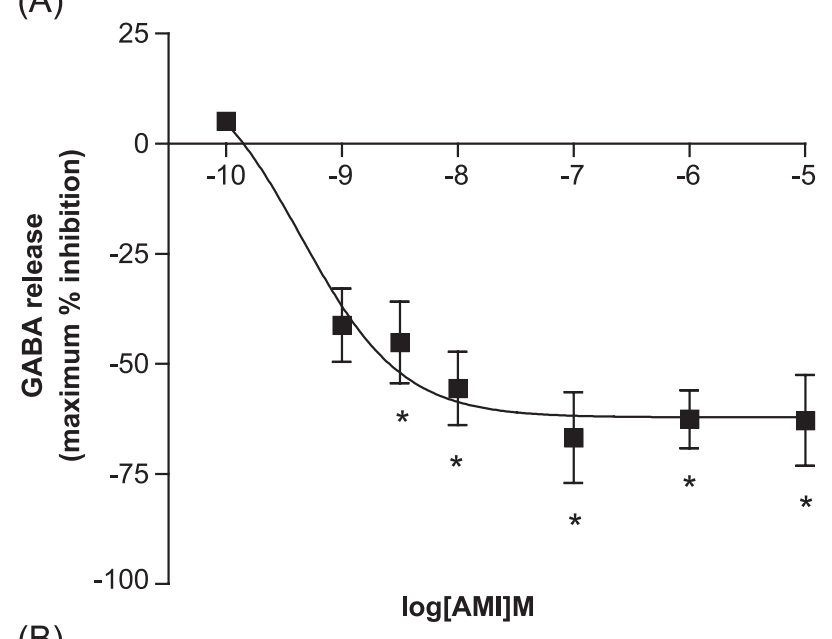

(B)

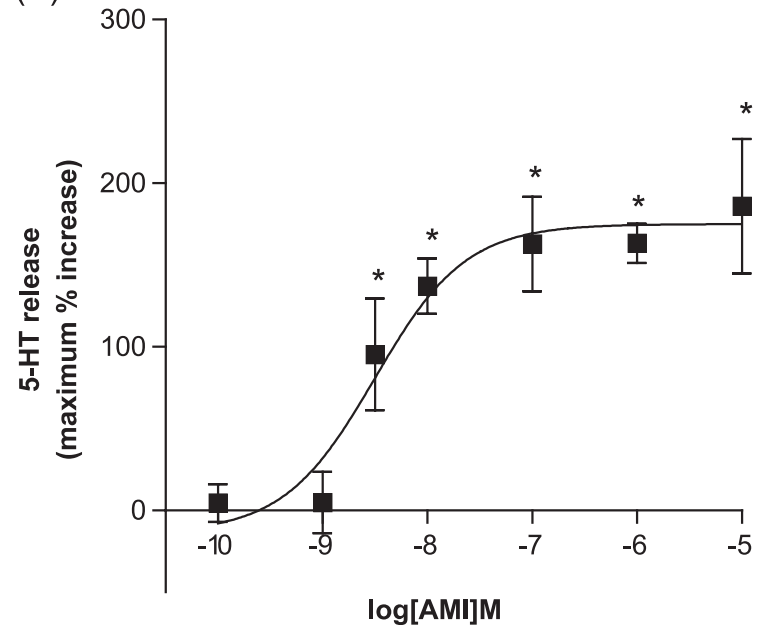

Fig. 6. Dose-response curve of AMI-193 $\left(10^{-9}\right.$ to $\left.10^{-5} \mathrm{M}\right)$ effect on GABA (panel A) and 5-HT release (panel B) from rat cortical slices. The points represent the maximal effect for each AMI-193 concentration expressed as percent change of release compared to basal. Each point is the mean \pm S.E.M. of four to six experiments. Significance of differences between experimental groups are calculated vs. control group by GLM for repeated measures $\left({ }^{*} p<0.05\right)$.

$0.1 \mu \mathrm{g} \mu \mathrm{l}^{-1}$ was followed by a gradual, long lasting and irregular increase in GABA levels lasting about $4 \mathrm{~h}$. The AUC increase was statistically significant $(F=6,795$; $p=0,048)$, as shown in the inset in Fig. 9 .

\section{Discussion}

TRZ is a weak inhibitor of the 5HT transporter (Frazer 1997), as confirmed in our experiments by the difference between the $\mathrm{pIC}_{50}$ of TRZ and the SSRI citalopram on $\left[{ }^{3} \mathrm{H}\right] 5$-HT uptake by isolated cortical synaptosomes. In the same preparation, Garrone et al. (2000) demonstrated that TRZ is devoid of 5-HT releasing effect. However, systemic TRZ administration results in a large increase in 5-HT extracellular levels in the rat cerebral cortex (Pazzagli et al., 1999). The present experiments indicate that TRZ increases 5-HT levels through a dual mechanism: at low concentrations, by attenuating an inhibitory GABAergic tone regulating 5HT release in the cerebral cortex, at high concentrations by inhibiting the 5-HT transporter. We observed that, in cortical slices, TRZ added to the perfusion fluid at concentrations ranging from $10^{-10}$ to $10^{-7} \mathrm{M}$ brings about a decrease in GABA release. The onset of the decrease is slow and, concomitantly with the lowest GABA level, an increase in 5HT release takes place. The hypothesis that the 5-HT increase may be triggered by a GABA decrease is supported by the observation that also the blockade of $\mathrm{GABA}_{\mathrm{A}}$ receptors by bicuculline elicits a dose-dependent increase in 5-HT release. Furthermore, in the microdialysis experiments, TRZ injection at the dose of $1.25 \mathrm{mg} / \mathrm{kg}$ was followed by
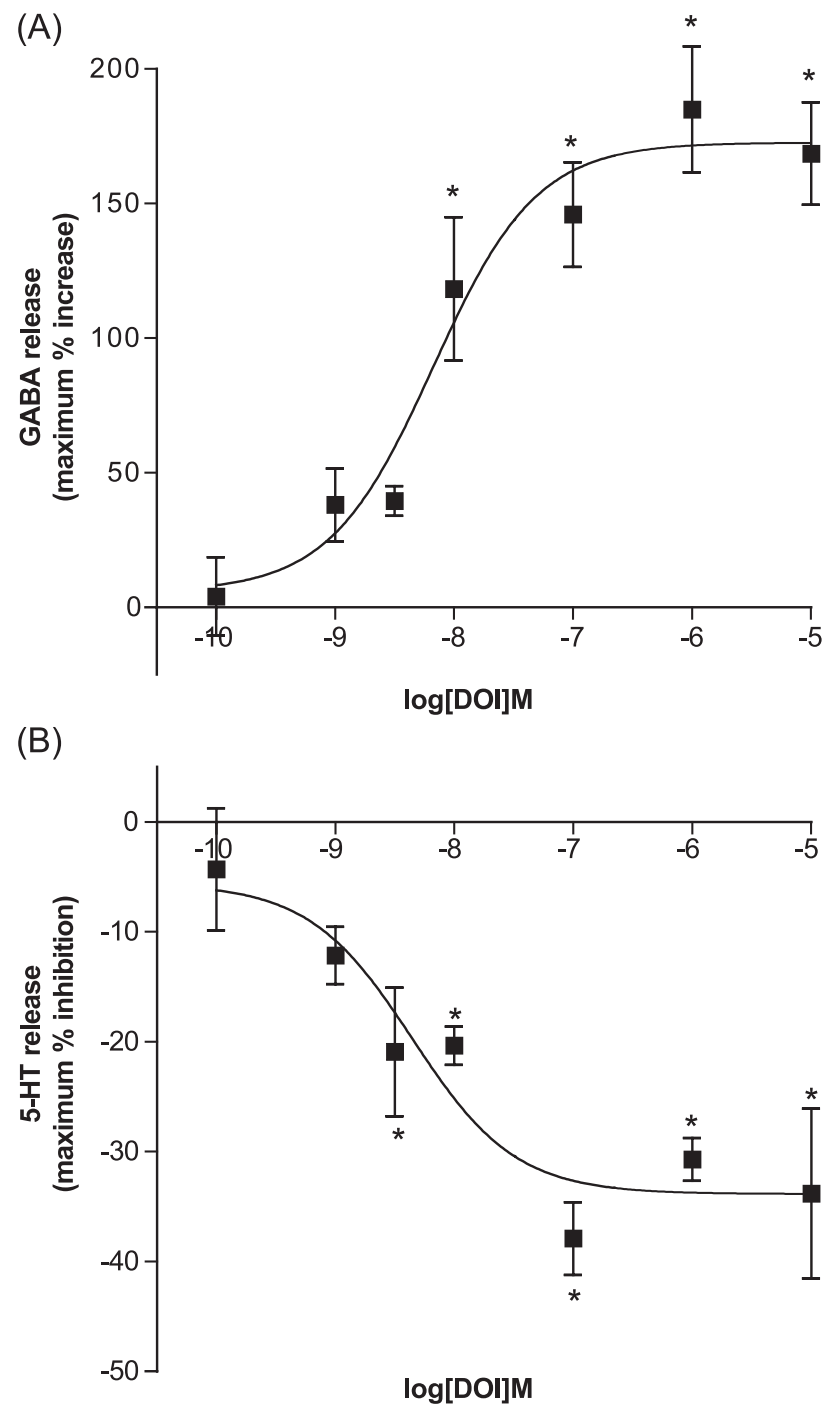

Fig. 7. Dose-response curve of $( \pm)$ DOI $\left(10^{-9}\right.$ to $\left.10^{-5} \mathrm{M}\right)$ on GABA (panel A) and 5-HT (panel B) release from rat cortical slices. The points represent the maximal effect for each $( \pm)$ DOI concentration expressed as percent change in release compared to basal. Each point is the mean \pm S.E.M. of four to six experiments. Significance of differences between experimental groups are calculated vs. control group by GLM for repeated measures $\left({ }^{*} p<0.05\right)$. 


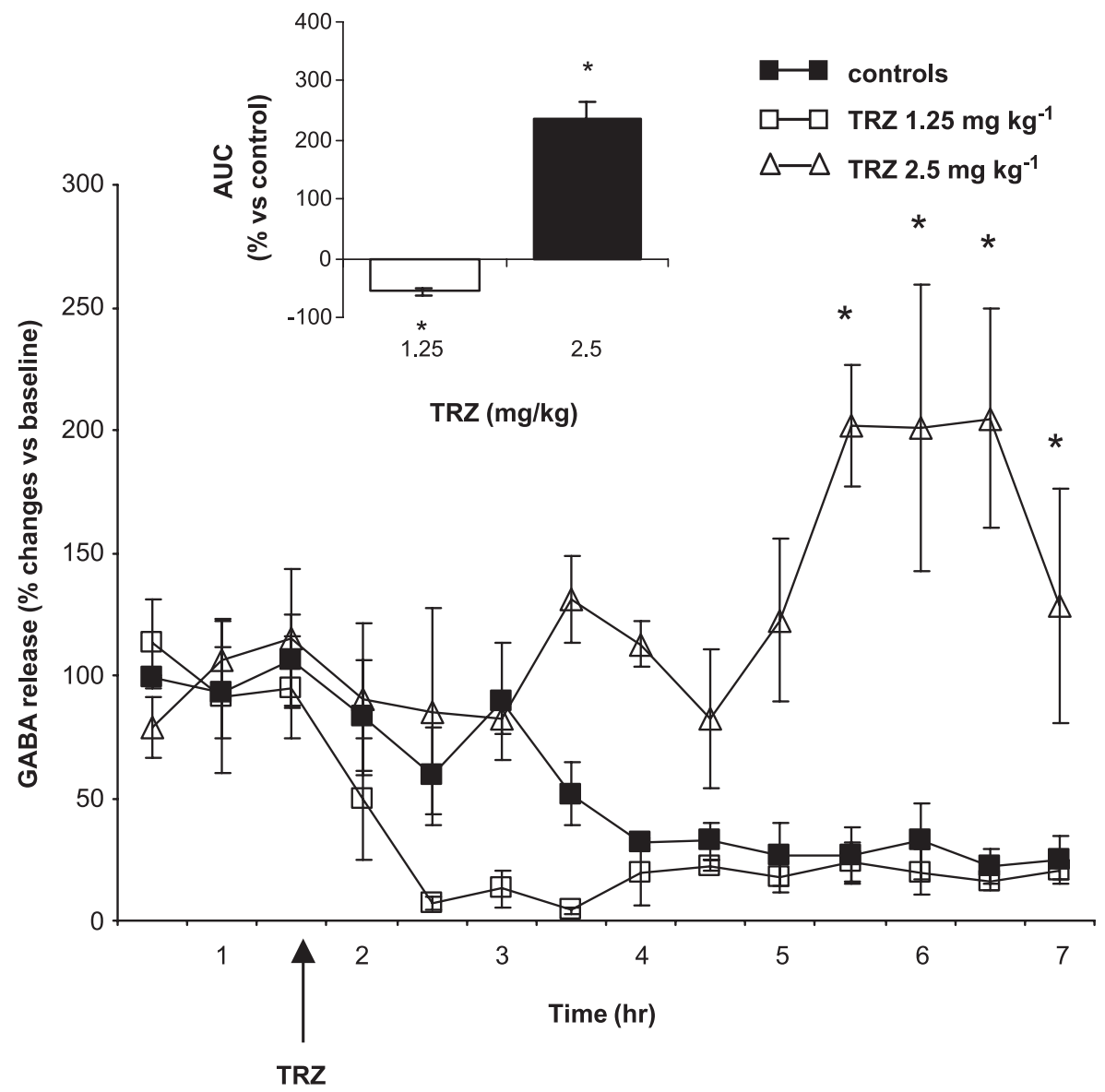

Fig. 8. Effect of TRZ administration on extracellular GABA levels in rat frontal cortex. The first three 30-min samples are taken as baseline and all values are normalized as percentage of baseline levels. TRZ was administered at the arrow. Inset: the bars represent the AUC values calculated from the second to the fourth hour $\left(1.25 \mathrm{mg} \mathrm{kg}^{-1}\right)$ and from the third to the seventh hour $\left(2.5 \mathrm{mg} \mathrm{kg}^{-1}\right)$. Open bar: TRZ $1.25 \mathrm{mg} \mathrm{kg}^{-1}$; black bar: TRZ $2.5 \mathrm{mg} \mathrm{kg}$. . Each point is the mean \pm S.E.M. of three animals for each group. Significance of differences between experimental groups are calculated vs. control group by GLM for repeated measures $\left({ }^{*} p<0.05\right)$.

a long lasting decrease in GABA outflow. Under the same experimental conditions and with the same dose, Pazzagli et al. (1999) observed a large increase in 5HT release beginning at approximately the time when the lowest extracellular GABA levels were observed in the present experiments.

GABA extracellular levels measured by microdialysis are an indication of GABAergic neuron activity since GABA basal levels are reduced and their evoked changes prevented by TTX perfusion (Bianchi et al., 2003).

Since in synaptosomes TRZ antagonizes the increase in GABA release induced by DOI, a partial $5-\mathrm{HT}_{2 \mathrm{a} / \mathrm{c}}$ agonist (Appel et al., 1990), and in cortical slices AMI-193, a 5$\mathrm{HT}_{2 \mathrm{~A}}$ antagonist (Ismaiel et al., 1993) inhibits GABA release and enhances 5-HT release, it may be assumed that the effect of TRZ is mediated through $5 \mathrm{HT}_{2 \mathrm{~A}}$ receptors.

An interaction between GABAergic and serotoninergic systems was demonstrated in the raphe nuclei where the bodies of the serotonergic neurons are located. According to Tao and Auerbach $(2000,2003)$, the infusion of the GABA antagonist bicuculline produced a large increase in 5-HT release within the dorsal raphe. Conversely, the infusion of the $\mathrm{GABA}_{\mathrm{A}}$ agonist muscimol inhibited the 5-HT release. From these experiments the authors concluded that GABAergic neurons exert a tonic inhibitory influence on the 5-HT neurons of the dorsal raphe nucleus. However, there is no information on a serotoninergic control of GABAergic neurons in this area. Summer et al. (2003) demonstrated that also in the lizard brain retrograde perfusion with GABA results in a significant inhibition of 5-HT overflow.

According to Harandi et al. (1987), there are many GABAergic interneurons in the dorsal raphe which impinge on 5-HT neurons. Since in our "in vitro" experiments, synaptosomes and cortical slices are obviously disconnected from the raphe nuclei, it appears that a GABAergic regulation of 5-HT release also exists in the cerebral cortex directly on the nerve endings. In the cortex a widespread GABAergic network exists and is formed by interneurons (Fonnum, 1987) and subcortical projections (Giovannini et al., 1997).

Abi-Saab et al. (1999) demonstrated that in the rat cerebral cortex the local administration of the $5-\mathrm{HT}_{2 \mathrm{a} / \mathrm{c}}$ agonist $( \pm)$ DOI increases GABA release, presumably by 


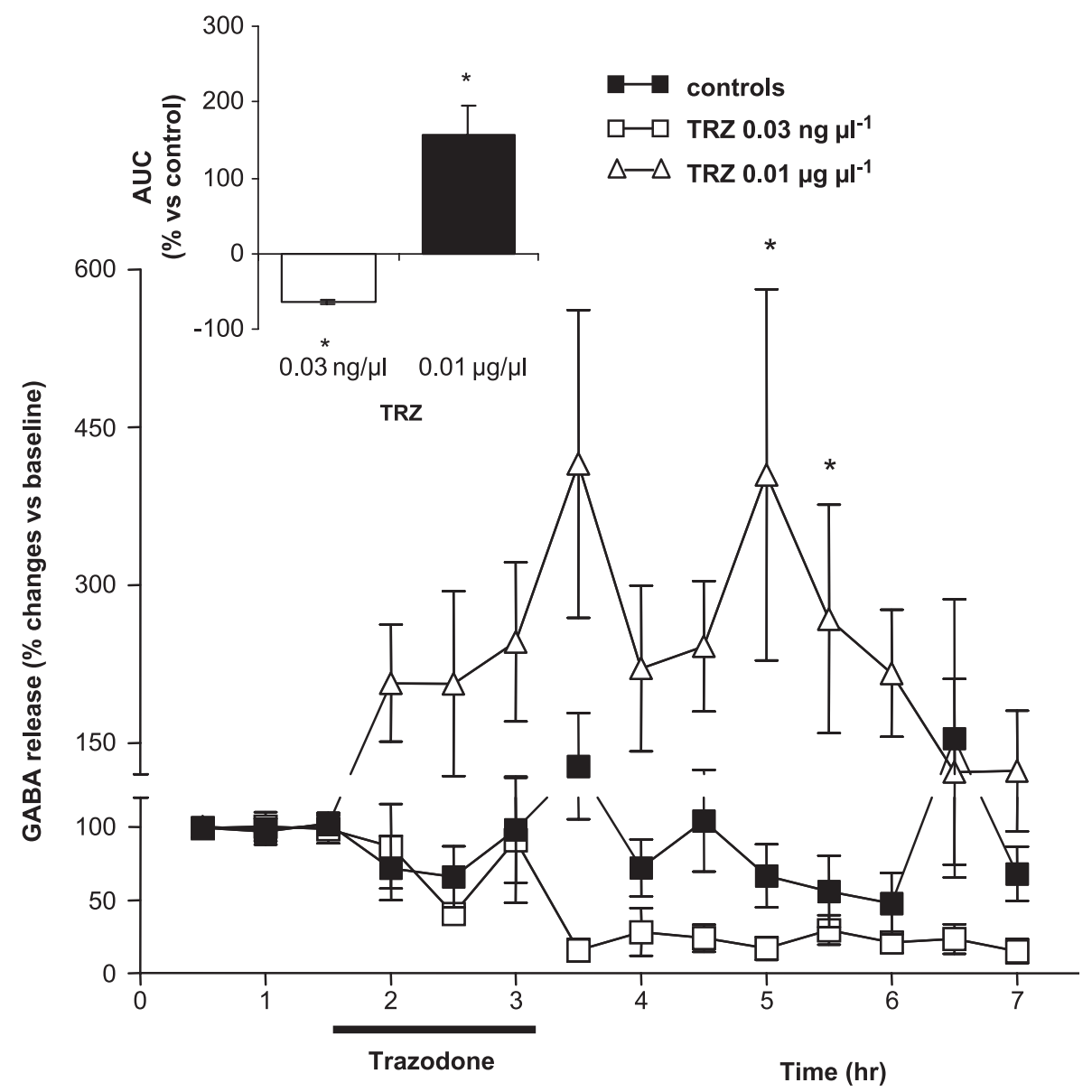

Fig. 9. Effect of local administration by reverse dialysis of TRZ on extracellular GABA levels in rat frontal cortex. The first three 30-min samples are taken as baseline and all values are normalized as percentage of baseline levels. TRZ was perfused for 90 min as indicated by the horizontal bar under the abscissa. Inset: the bars represent the AUC values calculated from the third to the seventh hour for TRZ $0.03 \mathrm{ng} \mu \mathrm{l}^{-1}$ (open bar), and from the beginning of superfusion to the seventh hour for $0.1 \mu \mathrm{g} \mu \mathrm{l}^{-1}$ (black bar). Each point is the mean \pm S.E.M. of four to seven animals. Significance of differences between experimental groups are calculated vs. control group by GLM for repeated measures $\left({ }^{*} p<0.05\right)$.

acting on receptors located GABAergic interneurons. In our experiments, $( \pm)$ DOI increased GABA release also from cortical synaptosomes, a finding which confirms a local a modulation of the GABAergic system by 5-HT. Prefrontal cortex interneurons are the major target of 5-HT neurons (Smiley and Goldman-Rakic, 1996). However, also the $\alpha_{1}$ agonist phenylephrine increased GABA release from the synaptomes in agreement with the noradrenergic modulation of cortical GABAergic cell types reported by Kawaguchi and Shindon (1998). The increase in GABA release induced by $( \pm)$ DOI, and phenylephrine was antagonized by TRZ but the $\mathrm{pIC}_{50}$ toward $( \pm)$ DOI was 200 folds larger than that toward phenylephrine demonstrating a higher affinity of $\mathrm{TRZ}$ for $5 \mathrm{HT}_{2 \mathrm{a} / \mathrm{c}}$ receptors than for $\alpha$ receptors, in agreement with Marek et al. (1992) and Frazer (1997). Taken together, these data indicate that cortical GABA interneurons modulate 5-HT release but in turn they are under serotoninergic control through $5 \mathrm{HT}_{2 \mathrm{a}}$ subtype receptors. The serotoninergic control of GABAergic inhibition in the prefrontal cortex has been recently examined by Yan (2002).
The reciprocal control between 5-HT and GABA neurons may explain the biphasic effect of TRZ on GABA release. At concentrations of $10^{-4} \mathrm{M}$, at which the 5-HT transporter is inhibited, there is a rapid increase in 5-HT release in cortical slices associated with an increase in GABA release presumably resulting from an immediate agonistic effect of 5-HT on GABA interneurons in competition with TRZ for the same $5-\mathrm{HT}_{2 \mathrm{a}}$ receptors. A large increase in GABA extracellular levels was also observed in vivo after the administration of TRZ $2.5 \mathrm{mg} / \mathrm{kg}$ i.p. A feedback loop in which a 5-HT-induced increase of GABAergic tone, through $5 \mathrm{HT}_{2 \mathrm{a}}$ receptors, results in the suppression of firing of a subpopulation of 5-HT neurons was described by Liu et al. (2000) in the dorsal raphe nucleus.

In addition to the presence of 5-HT2a receptors on GABAergic interneurons, 5HT2a receptors are also located on pyramidal neurons in the cortex, as shown by Jakab and Goldman-Rakic (1998), and mediate 5-HT excitatory actions (Aghajanian and Marek, 2000). The blockade of these receptors by TRZ may also contribute to its antidepressant activity. 


\section{Conclusion}

In the present study we demonstrated that TRZ induces a reciprocal modulation between the cortical serotoninergic and GABAergic systems. At low concentrations, TRZ decreases GABA release by removing a serotoninergic tone acting through $5-\mathrm{HT}_{2 \mathrm{a}}$ receptors on GABA neurons. In turn, the decrease in GABA level is accompanied by an increase in 5-HT release. At high concentrations, TRZ increases 5HT release by inhibiting its transporter. The increase in 5HT release, resulting from this double mechanism, may be responsible for the antidepressant properties of TRZ, possibly through a $5 \mathrm{HT}_{1 \mathrm{~A}}$ receptor downregulation (Subhash et al., 2002). The 5-HT increase is accompanied by a rise in GABA release. The interaction between the GABAergic and serotoninergic systems may explain the sedative, anxiolytic actions that accompany TRZ antidepressant activity.

\section{Acknowledgements}

The experiments carried out in the Department of Pharmacology, University of Florence were supported by a grant from ACRAF, Angelini Ricerche.

\section{References}

Abi-Saab, W.M., Bubser, M., Roth, R.H., Deutch, A.Y., 1999. 5-HT receptor regulation of extracellular GABA levels in the prefrontal cortex. Neuropsychopharmacology 20, 92-96.

Aghajanian, G.B., Marek, G.J., 2000. Serotonin model of schizophrenia: emerging role of glutamate mechanisms. Brain Res. Brain Res. Rev. 31, $302-312$.

Appel, N.M., Mitchell, W.M., Garlick, R.K., Glennon, R.A., Teitler, M., De Souza, E.B., 1990. Autoradiographic characterization of $( \pm)-1-(2,5-$ dimethoxy-4-[ $\left[{ }^{125} \mathrm{I}\right]$ iodophenyl)-2-aminopropane ([ $\left.{ }^{125} \mathrm{I}\right]$ doi) binding to $5 \mathrm{HT}_{2}$ and $5 \mathrm{HT}_{1 \mathrm{c}}$ receptors in rat brain. J. Pharmacol. Exp. Ther. 255, $843-857$.

Baldessarini, R.J., 2001. Drugs and the treatment of psychiatric disorders: depression and anxiety disorders. In: Hardman, J.G, Limbird, L.E. (Eds.), Goodman \& Gilman's The Pharmacological Basis of Therapeutics, 10th ed. McGraw-Hill, New York, NY, pp. 447-483.

Bel, N., Artigas, F., 1992. Fluvoxamine preferentially increases extracellular 5-hydroxytryptamine in the raphe nuclei: an in vivo microdialysis study. Eur. J. Pharmacol. 229, 101-103.

Bianchi, L., Ballini, C., Colivicchi, M.A., Giovannini, M.G., Pepeu, G., 2003. Investigation on acetylcholine, aspartate, glutamate and GABA extracellular levels from ventral hippocampus during repeated exploratory activity in the rat. Neurochem. Res. 28, 565-573.

Blier, P., De Montigny, C., 1994. Current advances and trends in the treatment of depression. Trends Pharmacol. Sci. 15, 220-226.

Bradford, M.M., 1976. A rapid and sensitive method for the quantitation of microgram quantities of protein utilizing the principle of protein-dye binding. Anal. Biochem. 72, 248-254

Cozzi, N.V., Nichols, D.E., 1996. 5-HT 2 A receptor antagonists inhibit potassium-stimulated $\gamma$-aminobutyric acid release in frontal cortex. Eur. J. Pharmacol. 309, 25-31.

DeVane, C.L., 2000. Pharmacologic characteristics of ideal antidepressants in the 21 st century. J. Clin. Psychiatry $61,4-8$.
Fonnum, F., 1987. Biochemistry, anatomy, and pharmacology of GABA neurons. In: Meltzer, H.Y. (Ed.), Psychopharmacology: The Third Generation of Progress. Raven Press, New York, pp. 73-182.

Frazer, A., 1997. Antidepressants. J. Clin. Psychiatry 58, 9-25.

Fuller, R.W., Snoddy, H.D., Cohen, M.L., 1984. Interactions of trazodone with serotonin neurons and receptors. Neuropharmacology 23, 539-544.

Garrone, B., Crudo, G., Luparini, M.R., Ruggieri, A., Pinza, M., 2000. Trazodone dose-dependently modulates GABA and serotonin transmission in rat cortical synaptosomes and slices. Eur. J. Neurosci. 12,144 .

Giovannini, M.G., Giovannelli, L., Bianchi, R., Kalfin, R., Pepeu, G., 1997. Glutamatergic modulation of cortical acetylcholine release in the rat: a combined in vivo microdialysis, retrograde tracing and immunohistochemical study. Eur. J. Neurosci. 9, 1678-1689.

Gray, E.G., Whittaker, V.P., 1962. The isolation of nerve endings from brain: an electron microscopic study of cell fragments derived by homogenization and centrifugation. J. Anat. 96, 79-87.

Harandi, M., Aguera, M., Gamrani, H., Didier, M., Maitre, M., Calas, A., Belin, M., 1987. $\gamma$-Aminobutyric acid, 5-hydroxytryptamine interrelationships in the rat nucleus raphe dorsalis: combination of radioautographic and immunocytochmical techniques at light and electronmicroscopy level. Neuroscience 21, 237-251.

Ismaiel, A.M., De Los Angeles, J., Teitler, M., Ingher, S., Glennon, R.A., 1993. Antagonism of 1-(2,5-dimethoxy-4-methylphenyl)-2-aminopropane stimulus with a newly identified $5-\mathrm{HT}_{2}$ versus $5-\mathrm{HT}_{1 \mathrm{C}}$-selective antagonist. J. Med. Chem. 36, 2519-2525.

Jakab, R.L., Goldman-Rakic, P.S., 1998. 5-Hydroxytryptamine2A serotonin receptors in the primate cerebral cortex: possible site of action of hallucinogenic and antipsychotic drugs in pyramidal cell apical dendrides. Proc. Natl. Acad. Sci. U. S. A. 20, 735-740.

Kawaguchi, Y., Shindon, T., 1998. Noradrenergic excitation and inhibition of GABAergic cell types in rat frontal cortex. J. Neurosci. 18, 6963-6976

Kilts, C.D., Breese, G.R., Mailman, R.B., 1981. Simultaneous quantification of dopamine, 5-hydroxytryptamine and four metabolically related compounds by means of reversed-phase high-performance liquid chromatography with electrochemical detection. J. Chromatogr. 225, $347-357$.

Liu, R., Jolas, T., Aghajanian, G.K., 2000. Serotonin 5- $\mathrm{HT}_{(2)}$ receptors activate local GABA inhibitory inputs to serotonergic neurons of the dorsal raphe nucleus. Brain Res. 873, 34-45.

Maione, S., Palazzo, E., Pallotta, M., Leyva, J., Berrino, L., Rossi, F., 1997. Effects of imipramine on raphe nuclei and prefrontal cortex extracellular serotonin levels in the rat. Psychopharmacology (Berlin) 134, 401-405.

Marek, G.J., McDougle, C.J., Price, L.H., Seiden, L.S., 1992. A comparison of trazodone and fluoxetine: implications for a serotonergic mechanism of antidepressant action. Psychopharmacology (Berlin) 109, $2-11$.

Owens, M.J., Morgan, W.N., Plott, S.J., Nemeroff, C.B., 1997. Neurotransmitter receptor and transporter binding profile of antidepressants and their metabolites. J. Pharmacol. Exp. Ther. 283, 1305-1322.

Paxinos, G., Watson, C., 1982. The Rat Brain in Stereotaxic Coordinates. Sydney: Academic Press.

Pazzagli, M., Giovannini, M.G., Pepeu, G., 1999. Trazodone increases extracellular serotonin levels in the frontal cortex of rats. Eur. J. Pharmacol. 383, 249-257.

Perovic, S., Muller, W.E., 1995. Pharmacological profile of hypericum extract. Effect on serotonin uptake by postsynaptic receptors. Arzneim.Forsch./Drug Res. 45, 1145-1148.

Raiteri, M., Angelini, F., Levi, G., 1974. A simple apparatus for studying the release of neurotransmitters from synaptosomes. Eur. J. Pharmacol. $25,411-414$.

Smiley, J.F., Goldman-Rakic, P.S., 1996. Serotonergic axons in monkeys prefrontal cerebral cortex synapse predominantly on interneurons as demonstrated by serial section electron microscopy. J. Comp. Neurol. $367,431-443$. 
Stahl, S.M., 1996. Antidepressants and mood stabilizers. In: Stahl, S.M. (Ed.), Essential Psychopharmacology. Cambridge Univ. Press, Cambridge, pp. 131-166.

Subhash, M.N., Srinivas, B.N., Vinod, K.Y., 2002. Alterations in $5 \mathrm{HT}_{1 \mathrm{~A}}$ receptors and adenylyl cyclase response by trazodone in regions of rat brain. Life Sci. 71, 1559-1567.

Summer, T.R., Matter, J.M., McKay, J.M., Ronan, P.J., Larson, E.T., Renne, K.J., Summers, C.H., 2003. Rapid glucocorticoid stimulation and GABAergic inhibition of hippocampal serotoninergic response: in vivo dialysis in the lizard anolis carolinensis. Horm. Behav. 43, $245-253$.
Tao, R., Auerbach, S.B., 2000. Regulation of serotonin release by GABA and excitatory amino acids. J. Psychopharmacol. 14, 100-113.

Tao, R., Auerbach, S.B., 2003. Influence of inhibitory and excitatory inputs on serotonin efflux differs in the dorsal and median raphe nuclei. Brain Res. 961, 109-120.

Tonnaer, J.A.D.M., Engels, G.M.H., Wiegant, V.M., Burbach, J.P.H., De Jong, W., De Wied, D., 1983. Proteolytic conversion of angiotensins in rat brain tissue. Eur. J. Biochem. 131, 415-421.

Yan, Z., 2002. Regulation of GABAergic inhibition by serotonin signalling in prefrontal cortex: molecular mechanisms and functional implications. Mol. Neurobiol. 26, 203-216. 